\title{
A CRITICAL REVIEW OF THE APPLICATION \\ OF MASLOW'S MOTIVATION THEORY IN INDUSTRY
}

\author{
JULIAN BARLING \\ DEPARTMENT OF PSYCHOLOGY \\ UNIVERSITY OF THE WITWATERSRAND
}

\begin{abstract}
OPSOMMING
Die toepassing van Maslow se motiveringsteorie binne die bedryfsituasie word hersien. Hoewel dit dikwels toegepas word, is die bruikbaarheid en die toepasbaarheid daarvan in sulke situasies nog nie met sekerheid bevestig nie. 'n Onderskeid word getref tussen die studies wat die toepasbaarheid en die wat die bruikbaarheid daarvan, vir die industriële situasie, bepaal. Die noodsaaklikheid van verdere navorsing, in besonder om vas te stel of daar ' $n$ verband bestaan tussen die selfvervullingsbehoefte en produktiwiteit, (bv. die bruikbaarheid van die teorie vir die organisasie) word besonder beklemtoon. Ten slotte word gesuggereer dat die teorie, in terme van die kriteria van voorspelling en kontrole van gedrag in organisasies, tekort skiet as 'n arbeidsmotiveringsteorie.
\end{abstract}

Maslow's theory of motivation (Maslow, 1968, 1970) has frequently been applied within the industrial and organizational context (cf. Maslow, 1965). Yet empirical research conducted to assess its validity and utility in industry does not adequately support such an application (Wahba \& Bridwell, 1976). The aim of the present article is thus critically to review and evaluate this application.

Before starting this review, it is essential to present the three major tenets of Maslow's theory. First, each individual is prepotently (i.e., predominantly) motivated by any one of five basic needs, which in ascending order, are the need for basic physiological necessities, the need for safety, the need for love and belongingness, the need for esteem and finally the need for self actualization (Maslow, 1970). These needs are basic in terms of the speculation that they are separate entities and are operative to a lesser or greater extent in all individuals. Whether the need for self actualization can be considered basic is questionable however, as Maslow (1964 \& 1968) maintained that satisfied individuals evidence no cravings of a particular need. Nonetheless, Maslow (1965 \& 1971) also pointed out that the need for self 
actualization could never be satisfied; rather, once the four lower order needs are satisfied, the need for self actualization increases as it is fulfilled. In terms of this speculation, it is doubtful whether the self actualization need is "basic". The second tenet is that once a need is satisfied, it no longer serves as the prepotent motivator of the individual's behavior, who then moves on to be motivated by the next highest need in the hierarchy. The final tenet is that self actualization is the highest need according to which an individual can be motivated. In terms of the application of this theory to the industrial situation, Maslow (1965) implied that should an individual be motivated by this need, his productivity should be enhanced both qualitatively and quantitatively. An examination of the literature reveals that this crucial, yet basic assumption has not been empirically evaluated, which is essential if the ultimate utility of this theory in the organizational context is to be established.

Maslow's theory of motivation was derived from what he categorized as 20 years of personality study, coupled with 12 years of therapeutic work and research on a sample of "personal acquaintances and friends .... public and historical figures" (1970, p.150), i.e., a small, nonrandom proportion of the total population in a clinical setting. Wahba and Bridwell (1976), in fact, refer to it as "a clinically derived theory" (p.235), while Maslow (1965) himself pointed out that the majority of support for his theory derives from the work of psychotherapists (e.g., Fromm and Rogers); the applicability of this theory in the industrial situation therefore remains an open question.

\section{The application of Maslow's theory of motivation to industry.}

It is important to point out that the application of Maslow's theory to the industrial situation makes a basic, but implicit assumption, namely that individuals necessarily believe that they can satisfy their needs both at their work and through their work. This assumption itself however, does not seem to have been the basis for any empirical research. To some extent, this assumption also serves to point to the difference between what may be regarded as work motivation, and motivation in general.

Blackler and Williams (1971) state that Maslow's theory was first presented to the business world by Douglas McGregor in 1960. This presentation was not carried out in the terminology normally associated with Maslow's theory, but rather in terms of the now wellknown Theory $\mathrm{X}$ and Theory Y formulation. Furthermore, it is important to point out that Hill (1974) states that it was only quite late in Maslow's career that he showed any interest in the possible application of his theory to the problems of management and industry, as well as to 
the problem of the motivation of the individual in organizational settings. Consequently, it is essential to note that when Maslow originally conceived of the major part of his theory of motivation, he did not have its specific application to organizational settings as a major aim. Hill's (1974, pp.47 \& 48) statement that: "His writings on this theme remain a drop in the ocean of his total output in psychological and other learned journals" further indicates that Maslow was essentially a thinker rather than a businessman or a manager.

What then, prompted Maslow's involvement in the industrial situation? Huizinga (1970) states that Maslow introduces his concept of eupsychian management since he objected to McGregor's (1960) formulations which were felt to be too static, in that they neglected the importance of the dynamic nature of motivation. Maslow therefore chose the adjective "eupsychian" as a descriptor encompassing all that was meant by Theory Y, synergy and the fostering of psychological health (which implies successful growth through the assumed hierarchy of needs) .

According to this approach, the fundamental duty of the organization is to enhance the psychological health of the individual employee. Huizinga (1970) points out that Maslow proposed that companies that did this should therefore receive tax while organizations which failed to accomplish this fundamental duty should incur tax penalties, since such a negative act could, and should, be regarded as an act of sabotage aimed against the whole of society. The (related) point was also made that such managerial practices cannot work unless the managers and supervisors themselves are quite ready for it. Hence Maslow (1965) speculated that this managerial philosophy could not work in "authoritarian" countries, and cited Iran, Syria and South Africa as examples. It is important to point though, that this broad assumption has never been tested transnationally.

Although Maslow (1965) maintained that the aim of enlightened management should be to enhance the self actualization of all individuals within the organization, he did point out that too much of modern management philosophy ignores the question of values. Furthermore, he maintained (Maslow, 1961) that the demands of modern society, which emphasized results, stultified any possibility of creativity within organizations. This would be undesirable as the possibility of the individual's self actualization being enhanced in the organization would be reduced. Maslow thus accepted that organizations would always exist, yet would not necessarily foster and encourage their employees' self actualization.

Maslow (1971) posed the question of the relationship and duty between the individual and the organization, and asked how (self actualized) individuals could be used and treated in 
the optimal interests of the organization. He maintained that eupsychian conditions were best for the organization in terms of both the quality and quantity of the products the individual would produce under such conditions. Consequently, the problem facing management would be how to set up those conditions which would foster and facilitate an eupsychian situation in which the goals of the individual and the organization would be congruent. This was felt to be important by Maslow, who specifically pointed out that: "The more grown people are, the worse authoritarian management will work, the less well people will function in an authoritarian society, and the more they will hate it" (1971, p.261). It can therefore be seen that not only do society, the enlightened organization and the self actualized individual have a reciprocal relationship between themselves but, according to Maslow's formulations, they also have a fundamental duty to each other. This acquires more importance when considering the vast majority of individuals who do not have the resources, either financial or personal, to enter into long-term individual psychotherapy, which could be another means of achieving personal growth.

Within the framework of the organization, it would be well though to realize that self actualization is more than likely a high complex variable. O'Reilly (1973) pointed out that a subordinate's self actualization could well be influenced by his supervisor's perception of his abilities; should this supervisor have a deflated opinion of his subordinate and his abilities, these abilities might not be utilized to their fullest potential. Hence, the importance of managers themselves being self actualized or psychologically healthy becomes more obvious. Such individuals by definition have a more efficient and realistic perception of reality (Maslow, 1970). This could increase the subordinate's self actualization which might then result in an increase in both the quality and quantity of work.

A further problem arises when Maslow's (1971, p.33) description of self actualized individuals is examined, viz. "A musician must make music, an artist must paint, a poet must write, if he is to be ultimately happy. What a man can be, he must be". It is quite feasible that should the needs of the individual and the organization not coincide, the individual's ability, creativity and personal interests might not be utilized at all within the organization. On the other hand, should organizations cater for all the individuals' needs without regard for its own idiosyncratic needs, it is indeed, doubtful whether such organizations could survive. Thus Eilon (1975, p.655) concludes that: "Self actualization for all is a myth", which has farreaching implications, since Maslow hypothesized that the productivity of self actualized people would be qualitatively and quantitatively enhanced. 


\section{Studies interpreted as evidence for Maslow's motivation theory in industry}

Many studies have been carried out since the late 1940's which attempt to ascertain the needs of individuals of different occupational levels. At about the same time, Maslow's theory of motivation began to achieve general acceptance, and many of these studies were then re-interpreted as constituting evidence for Maslow's need hierarchy. It might be well therefore to examine briefly some of these studies.

In one of the first of these investigations, Centers (1948) conducted a study on the adult White male population of the United States. Using standardized person-to-person interviews, Centers (1948) found that people in the upper echelons of the occupational hierarchy were more satisfied with their jobs and vice versa. Furthermore, he maintained that individuals in higher occupational levels had a greater preference for self expression, while other individuals were more concerned with security. On the basis of open-ended interviews, Lyman (1955) also maintained that there was a difference between the higher and lower occupational levels in that white collar workers emphasized the importance of the intrinsic nature of the work, with blue collar workers emphasizing the physical nature of the work more often. On the basis of person-to-person interviews during which 692 respondents ranked the various factors important in their jobs, Centers and Bugental (1966) maintained that the same phenomena existed, but pointed out that such differences could be merely circumstantial.

Huizinga (1970) cited three studies as being supportive of Maslow's motivational model. First, Gurin, Veroff and Feldt (at pp.97 \& 98) made the point that it would appear that the higher needs are more important for people higher in the occupational hierarchy who are correspondingly not really concerned with the lower order needs. Secondly, Blai (at p. 101) found that self actualization was valued more often by those occupying the upper occupational levels, while the lower socioeconomic status groups more frequently chose the more prepotent needs. Similarly, Friedlander (at pp.99-101) maintained that blue collar workers place more importance on safety needs. Friedlander concluded however, that one's values are a function of one's occupational culture, which tends to support Hall and Nougaim's (1968) career stages model (to be discussed) more than Maslow's hierarchy of basic needs. Contrary to all these findings however, Pigors and Myers (1969, p.624) state that: "Recent research in motivation has exploded the myth that high level needs are important only to high level employees". Yet Pigors and Myers (1969) do not explicitly state the research upon which they base this statement, which thus remains a questionable proposition. 
In summarizing these studies, it is necessary to point to a few salient issues. First, most of them claimed to provide support for Maslow's dynamic need hierarchy, while utilizing cross-sectional data. At this stage, it must therefore be questioned whether a cross-sectional study can provide either support for the dynamic nature of the need hierarchy, or any information at all about cause-effect relationships. It is further contended that any assumptions about cause-effect relationships are merely inferences from the data. A further important point is that most of the above studies were examining the individual's preferences. The question therefore arises as to whether it is possible to automatically equate such preferences with the motivation to work. Furthermore, it is doubtful whether studies not specifically designed to assess aspects of Maslow's theory can in fact, validate any aspects of the theory. Consequently, it is doubtful whether these studies provide any useful information regarding the application of Maslow's theory of motivation to the industrial situation as a theory of work motivation.

\section{Empirical studies of Maslow's theory of motivation applied in industry}

Any results from empirical studies designed to test Maslow's is from such studies that its validity and applicability in such situations can be assessed. Despite the crucial importance of such research, it becomes apparent that not much research exists concerning Maslow's theory in the area of management and industry. In fact, Hall and Nougaim (1968, p.13) make the cogent point that: "Despite the popularity of Maslow's model, there has been comparatively little work done to test it empirically". Parke and Tausky (1975) maintain that there is little empirical evidence for the concept of a self actualization need, and speculate that the belief in this need has actually retarded organizational analysis, since explanations derived from this belief are simplistic and illusory. Apart from investigations in the work environment reported in this article, no major attempt has been made to establish the empirical status of Maslow's theory in general. This is perhaps understandable however, in terms of Alderfer's (1969, p.151) statement that as the need hierarchy is ascended the needs are less concrete, and that " ... the continuum from more to less concreteness is also a continuum from more to less verifiability ...."

Possibly one of the most broad, rigorous and self critical of the studies undertaken in the area is that of Huizinga (1970). This study was conducted for a number of reasons. First, Huizinga (1970) was of the opinion that Herzberg's general findings (cf. Grigaliunas \& Weiner, 1974) could be explained within the framework of Maslow's need hierarchy, and 
secondly that the work situation serves an important function in the individual's life. A further reason was that Huizinga (1970) felt that industrial psychology lacked a sound theoretical base. Finally, he was concerned with Maslow's general theory, as well as with the potential contribution the concept of psychological health could make to a "positive psychology". Huizinga relied exclusively on paper-and-pencil questionnaires, as he maintained - following a review of the literature - that: "Open interviews are out of the question because one needs questionnaires of a very systematic design with carefully chosen items and precoded answers" (1970, p.114). Items were thus constructed according to Maslow's description of the needs so that they would be unequivocably interpretable in terms of the need categories, with a minimum of four items per need. Both motivation and satisfaction items had the same content in a different form, rated according to one of seven criteria, each representing a Maslowian need category or subcategory. The results strongly supported the contention that factors corresponding to the lower order needs in the work situation are more important for individuals of lower occupational levels. However, factors in an (hypothetical) work situation corresponding to the higher needs were not found to be as important for individuals of higher occupational levels. Huizinga (1970) maintained that these findings minimized the importance placed on the higher order needs (such as self actualization) in modern management literature; nevertheless, these findings alone are not sufficient to invalidate the dynamic nature of Maslow's need hierarchy.

Hall and Nougaim (1968, p.15) pointed out that they could not find any study which ".... explicitly employed his (i.e. Maslow's) need levels, and studied changes in need strengths and satisfaction in a panel of subjects over time". This would be essential to validate the dynamic relationship between the five needs, or if any useful information for an understanding of motivation were to be provided. Consequently, they undertook a longitudinal stud, as they stated that an assessment of the need hierarchy in action was required. Their study involved a five year follow-up 49 college graduates at management level in one organization, and needs were measured with interview data obtained from open-ended questionnaires. A content analysis on the data yielded nine categories, which were collapsed into four viz., self actualization, achievement and esteem, affiliation and safety. Coding was performed by two Ph.d candidates. Neither median inter-rater reliability for need strength (.59) or satisfaction (.55) was as high as the experimenters desired; both coders thus scored each case before arriving at final, jointly-determined scores. The following results emerged from this study. 
First, it was found that all satisfaction scores were positively correlated with the need strength in the first year. Secondly, all changes in need satisfaction from the first year to the next were positively correlated with changes in need strength at the next highest level; for both these analyses however, the correlations were not high.

A "success" analysis was then performed in which the individual's income was taken as a supposedly objective measure of the degree of need satisfaction over the five year period. On this basis, Hall and Nougaim (1968) pointed to the finding that in the first year, the "successful" group had evidenced a significantly lower safety need than their "less successful" colleagues, while both groups increased in their needs for achievement, esteem and self actualization over the same period. Only the "successful" group showed a significant increase in the need for affiliation, with the non-successful group evidencing a non-significant increase. At the completion of the five year period, the "successful" managers perceived their needs as being satisfied to a significantly greater extent than the "non-successful" group evidencing an insignificant increase. Nonetheless, differences over the five year period might have been due to factors outside the organization changing, as attempts were only made to hold organizational variables constant in the study.

Hall and Nougaim (1968) maintained that these results do not support an explanation favouring the concept of growth through the hierarchy. Instead, they favoured a "career stages" explanation, postulating that the higher order needs might be related to developing career concerns rather than psychological growth through the need hierarchy". Safety concerns would thus be manifest early in one's career, with achievement and esteem concerns occurring later.

In contrast to Maslow's model, the career stages hypothesis postulates that an individual would move on to the higher career stages as a result of regular status passages, which would be facilitated by both the individual and the environment. An examination of this model in the South African context however, (Barling, 1976), did not provide support for this alternative hypothesis. It is interesting to note that many cross-sectional studies claim to provide support for the dynamic nature of the hierarchy, while Hall and Nougaim's (1968) longitudinal study made no such claims. Nevertheless, Lawler and Suttle (1972) point to the following shortcomings in this study. First, the sample of only 49 individuals was rather small. Secondly, the data was based on post hoc coding of unstructured interviews, which were not designed to yield information specific to Maslow's theory, and thirdly there was only low 
agreement amongst the coders $(0,55-0,59)$. Consequently, any conclusions drawn from the Hall and Nougaim study must necessarily be viewed against these criticisms.

Lawler and Suttle (1972) maintained that for a study to be an adequate test of Maslow's theory, it is necessary to examine the consequences of changes in satisfaction, as well as the causal bases for such changes. To do this longitudinal data was necessary, since it is difficult to provide support for a dynamic or causal hypothesis solely with cross-sectional data. Two groups were used for their study, both of which were tested at the beginning of the experiment. One group was then tested six months later and the second group a year later, since the authors were not sure how long it would take for satisfaction to effect performance. Because of the nature of the time intervals, a "causal" correlation analysis could be performed as well as a "static" analysis. The cross-lagged, panel correlational analysis (Pelz and Andrews, 1964) was used for the dynamic correlational analysis, since this is able to show significant results where a third variable may cause the observed relationship between the first two variables. It does not however, establish causality.

Lawler and Suttle's (1972) first hypothesis was that satisfaction of needs at one level should correlate negatively with their own importance, and positively with the importance of the next highest need in the hierarchy. In both organizations studied, a significant positive correlation was manifested between satisfaction and importance of the security need, using the Porter Need Satisfaction Questionnaire (1961). Furthermore, a significant positive (but low) correlation was found between security satisfaction and the belongingness needs. The authors maintained that these results provide support for Maslow's dynamic hierarchy. Their final hypothesis was that high satisfaction of needs at a specific time - time 1 - should be associated with decreased importance of the same need at time 2, as well as with increased importance of the needs in the next highest category at time 2. The first findings for this hypothesis however, were not significant. Nonetheless, more changes seemed to occur from time 1 to time 2 within the lower order needs. On the basis of these results, the authors were not able to conclude that increased satisfaction at one level caused the importance of the need at the next highest level.

The authors maintained that the failure to conclusively support the need hierarchy might be due to the time during which the experiment was conducted not being sufficient to allow for changes. They also made the point that Maslow's model cannot be rejected on the basis of a few studies, and further question whether the items used actually tested Maslow's needs, a problem which might occur with all such studies, since the basic needs were not 
operationally defined for the organizational situation by Maslow (cf. Huizinga, 1970; and Wahba \& Bridwell, 1976). Lawler and Suttle (1972) maintain that in general there seemed to be more evidence for the existence of a two-level hierarchy, although they admit that their study could not really test this. Such a conception is not completely alien to Maslow's theory however, in view of his own conceptualization of a dichotomy between growth-related needs ("B-needs") and deficiency-oriented needs (“D-needs ”) (Maslow, 1968).

Using Porter's (1961) Need Satisfaction Questionnaire (PNS), Wofford (1971) found that the higher order needs were significantly related to job satisfaction both for individuals whose lower order needs were not satisfied, as well as those individuals whose lower order needs had been satisfied. This suggests that higher need levels influence job satisfaction even when lower order needs are not satisfied. Wofford (1971) further speculates that the evidence points to the needs operating in a complimentary, rather than a hierarchical manner; consequently this study does not tend to support the hierarchical nature of Maslow's need hierarchy.

Trexler and Schuh (1971) agreed with Hall and Nougaim (1968) that it is essential to obtain longitudinal data to be able to accept or reject the dynamic nature of the hierarchy. As the basis for their experiment, they questioned what would happen - in terms of Maslow's need hierarchy - if deprivation were introduced to a group of previously satisfied and healthy individuals. To study this, a pretest-posttest experimental design was utilized. The control group consisted of both male and female psychology students, while the experimental group consisted of 103 Naval volunteers. For the purposes of this study, the authors designed a questionnaire consisting of 31 items, with each need being measured by at least three items. A seven point rating scale was used, with the general instructions following those of Porter (1961). The instrument was administered to both groups in the first, fifth and ninth weeks (of the training program for the experimental group) during which time deprivation might be assumed to occur. A chi-square analysis showed that the experimental group regressed down the hierarchy to a significant degree, which supports Maslow's theory in that individuals were shown to regress (in terms of their prepotent need) when their previously fulfilled needs were subsequently deprived. Results from this study should be viewed rather tentatively however, since the same questionnaire was used three times over a nine week period, as well as the fact that no reliability data at all was reported for their questionnaire.

Alderfer's (1969) study is both interesting and important, as it provides an alternative to Maslow's theory on the basis of empirical research. Because of the extent of overlap between the five needs in Maslow's model (cf. Kendall, Note 2; Barling, Note 1), Alderfer (1969) 
postulated three needs, viz., existence (all forms of physiological and material desires), relatedness (involving significant relationships with all others, both friends and enemies) and growth (any creative need or productive effort on the part of the individual). Satisfaction of this growth need would arise from the continuous use and development of the individual's capability.

Alderfer (1969) provides a number of illuminating similarities and differences between his $E R G$ theory and Maslow's motivational model. He points out that as the $E R G$ hierarchy is ascended, the needs are less concrete and verifiable, which is possibly similar to Maslow's proposed hierarchy. Differences between the two theories also exist. First, the $E R G$ hierarchy is not rigid, and the lower order needs therefore do not have to be satisfied as a prerequisite for motivation by the higher order needs. Hill (1974) maintains, however, that the rank order of needs in Maslow's hierarchy was not meant to be particularly rigid. Perhaps of more importance is the crucial role the environment is assumed to fulfill in the $E R G$ theory; Maslow's theory, on the other hand, implies that an individual is born with what he will become. Furthermore, Alderfer (1969) maintains that more significant reliability and validity coefficients were found for $E R G$ theory when operationalized, precisely because of the difficulty in operationalizing Maslow's writings, a problem referred to by many authors.

Roberts, Walter and Miles (1971) conducted a factor analytic study utilizing 380 managers, while overall organizational climate and the individual's occupation were held constant. Supplementing the $N S Q$ with a few items, making minor modifications to others while retaining the same basic format, Roberts et.al. (1971) obtained mixed support for Maslow's theory. They found that only the esteem and "autonomy" needs could be interpreted in terms of Maslow's categorizations. (It must be noted though, that Maslow regarded autonomy as part of the esteem need; Porter (1961) however, excluded the physiological need and included the autonomy need as a separate category distinct from the esteem need, thus retaining a five need hierarchy. Other writers (e.g., Roberts, 1971; Payne, 1971 and Alderfer, 1969) followed this interpretation and included an autonomy need in their conceptualization of the hierarchy). However, the possibility exists that results from this study might differ from others due to method variance, as Huizinga (1970) points out that different researchers might interpret factor analytic results differently. This point should be kept in mind even should a factor analytic study confirm the existence of five basic needs, since method variance between such studies might well account for any differences. Furthermore, Wahba and Bridwell (1976) 
point out that factor analytic results are often a function of the data collected rather than the theoretical construct itself - hence the need for caution when interpreting such studies.

An extremely important point is that none of the above studies attempted to establish whether any relationship existed between the need for self actualization and productivity, which could be due to one (or both) of two reasons. First, as measures of absolute productivity are difficult to obtain, and secondly that there are no operational definitions of any of the five needs specific to the industrial context. This illuminates a critical distinction: studies reported to this point have attempted to assess whether Maslow's theory as a whole is applicable within the industrial context. On the other hand, no studies have been conducted specifically to assess the utility for the industrial situation of this particular theory, which is a separate conceptual issue. Assuming that aspirations for promotion might be an index of the individual's motivation to work, Barling (Note 1) found no significant relationship between the need for self actualization and the individual's promotional aspirations, using a sample of 69 White South African mineworkers. The question of whether the need for self actualization is related to the motivation to work, as might be reflected by enhanced productivity, is thus raised. This question is perhaps central to the issue of the utility of Maslow's motivational theory as a theory of work motivation since should a relationship not be found to exist between the need for self actualization and productivity, the theory would necessarily have limited utility for industrial and organization situations.

\section{Cross-cultural and cross-national studies of Maslow's theory applied to industry}

An examination of studies testing Maslow's theory in the industrial setting in various cultures is important for a number of reasons. Perhaps the most important is that Maslow himself maintained that this theory was universal. Hence, cross-cultural and cross-national studies are essential to assess this assumption. Should the theory not be universal, no justification for attempting to apply the theory in other cultural milieus would exist. In other words, cross-cultural and cross-national studies should attempt to delineate those situations in which the theory might be applicable. Sanford (1970) pointed to a further reason why Maslow's theory should be investigated cross-culturally. He claimed that together with all the trade that the United States was exporting to various Latin American countries (the focus of the article), "... many United States companies have exported United States management philosophy and theory" (1970, p. 145). However, it does not necessarily follow that such theories will be effective in all situations because of their effectiveness in one particular 
situation. Cross-cultural studies are therefore important since the values and norms of individuals in different countries and cultures might vary considerably. Because of the importance of this issue, Wahba and Bridwell's (1976) failure to discuss it is rather surprising.

Sanford (1970) did not question the existence of the basic needs but rather their rank order, because of the values that different cultures might instill. He therefore compared need importance and satisfaction in the United States and Latin American countries, without specifically stating which countries constituted the latter. Sanford's (1970) data were based on the findings of attitude surveys already reported in the literature. Generally, he found that Latin Americans viewed their work as the means by which they could satisfy their psychological needs, although this was not the case with the satisfaction of the safety needs. Thus Sanford (1970) speculated that these individuals might perceive other social institutions as the more important determinants of their safety satisfaction. Although the satisfaction of the social needs were important to these individuals, it is probable that these needs were satisfied by the extended family to a greater extent than they were satisfied at or by the individual's work. Moreover, it was not important for these individuals to gain self respect through their work, since their culture endowed them with feelings of both dignity and worth.

Sanford (1970) pointed out that an implicit assumption of Maslow's theory applied to industry is that it is possible to satisfy one's needs through the work situation. Thus it is not surprising that Sanford (1970) maintained that there is a negative attitude towards work in Latin American cultures, in terms of the American work ethic, given that their needs might be satisfied in other situations. The speculation that such individuals seek to self actualize through various intellectual and spiritual activities and not through their work is consequently quite feasible. Furthermore, these individuals appear to place their "inherent" dignity and worth, endowed upon them by their culture, as the most prepotent of all the needs. As an example, Sanford (1970) maintained that these individuals would often resign from their work if they were reprimanded, thereby jeopardizing their physiological needs in favour of the assumed esteem needs.

According to Sanford (1970) though, this does not necessarily mean that Maslow's theory is not applicable in such cultures; rather, it demonstrates that this theory might be more applicable within the United States than the Latin American countries. To increase its applicability for these Latin American countries, the theory might therefore have to be modified to conform more closely to these people's attitudes and values. Alternatively, according to Sanford (1970), these values and attitudes would have to be modified to conform more 
closely to the theory! It is debatable however, whether the second suggestion is at all practical.

Nonetheless, Sanford's (1970) speculations should be treated with considerable caution for a number of reasons. First, it was not a controlled study but rather a literature-type survey of attitude studies, i.e., the hypotheses advanced were not done so on the basis of a study in the "real world". Secondly, the actual groups falling under the umbrella term "Latin American" were not enumerated; the use of this extremely broad and unspecific term thus further limits any justified generalizations on the basis of this study. Furthermore, although Sanford (1970) hypothesized that Latin culture would become increasingly similar to that of the United States because of industrialization, empirical evidence shows that Mexican operatives emphasized need importance more than their counterparts (Slocum, 1971), which contradicts Sanford's (1970) speculation. Finally, in view of all this, there is certainly insufficient evidence to reject Maslow's theory on the basis of Sanford's (1970) general speculations.

Slocum (1971 ) and Slocum, Topichak and Kuhn (1971) compared the need satisfaction and importance of Mexican and American operatives on the NSQ. From these two empirical studies, it might again be suggested that culture influences the rank order of the need hierarchy for managerial personnel, which is consonant with Sanford's (1970) speculation. Furthermore, Slocum's (1971) evidence that Mexicans are more satisfied with the United States counterparts supported Sanford's (1970) general speculations.

In a study of the needs of 69 White mineworkers in a South African setting, Barling (Note 1) did not find conclusive evidence in support of the dynamic nature of the need hierarchy. However, such results should be treated with caution since cross-sectional data were used. The evidence did tend to favour the existence of an hierarchical relationship between the lower order needs however, which is consonant with Lawler's (1973) statement that results generally support such findings.

On the basis of structured interviews with a sample of urban Xhosa workers in South Africa, Backer (1973) found only $1 \%$ to be concerned with the self actualization need. This does not necessarily refute the need hierarchy concept however, since motivation by the self actualization need theoretically requires all the other needs to be satisfied which was not the case with this sample, as $70 \%$ were concerned with physiological needs; $18 \%$ with esteem needs; $9 \%$ with security needs; while only $2 \%$ were concerned with the satisfaction of "affiliation" needs. Should Maslow's (1965) hypothesis that self actualizers' productivity should be 
enhanced thus be correct, the utility of this theory in a situation where the vast majority of a group were concerned with the lower order needs would be highly questionable. An alternative hypothesis worthy of research might be the individual's most prepotentent need is related to enhanced work performance and productivity. Backer (1973, p.9) points out that Maslow's general theory is nonetheless interesting within the South African context, since it "... places emphasis on the presence of needs at various levels which call for satisfaction in man, and under what conditions these needs could be satisfied".

Blunt (1973) undertook a study of White middle-management in English speaking organizations in South Africa, and found that South African managers were more dissatisfied than their counterparts in England, America, Denmark, Australia, Germany, France and Italy in almost every need category. Combining Blunt's (1973) data with similar studies from a few other countries, Howell, Strauss and Sorensen (1975) conducted a similar study in Liberia on 130 middle mangers from ten different organizations. From all these studies, both Howell et.al. (1975) and Blunt (1973) concluded that the order of the need hierarchy seems less influenced by culture than need satisfaction, both studies using Porter's (1961) NSQ. This conclusion, however, does not seem to be congruent with the findings of Slocum (1971) and Slocum et.al. (1971). Blunt's (1971) results cannot be considered as definitive however, as the study was not designed to specifically assess Maslow-type categories.

Before concluding this section, one further point should be enumerated. All these studies might merely measure cross-cultural work preferences, or be testing the dynamic nature of the hierarchy of needs, or attempting to ascertain whether the rank order of needs in the hierarchy differs according to cultural groups. None of these studies specifically sets out to ascertain whether any relationship existed between the need for self actualization and productivity (or any other reliable measure of work motivation).

In conclusion, it can be seen from the above studies that although the basic studies do seem to appear across the different cultures investigated, the actual order or ranking of these needs vary according to the different cultures. It is thus possible to conclude that culture may influence the rank order of the different needs.

\section{Some criticisms of methodologies used to test Maslow's theory}

In a discussion of the applicability and utility of Maslow's motivation theory for the industrial situation, it is necessary briefly to evaluate the various techniques utilized to assess this theory within the industrial context. 
Although unstructured interviews have been utilized (e.g., Hall \& Nougaim, 1969), too many problems exist with such an approach (cf. Huizinga, 1970). The first is that of the subjectivity of the interviewers and the related problem of the coding of the data obtained. Secondly, and closely related to the first problem, is that which might be termed inter-coder reliability. Hence, although this method has been used previously, it is suggested that it is not sufficiently rigid methodologically which minimizes the importance of any results based on it.

The majority of questionnaires that have been used have been of the paper-and-pencil variety, most of which have made use of Porter's (1961) NSQ in some form or another (e.g., Trexler \& Schuh, 1971; Blunt, 1973; Howell, et.al., 1971). This is possibly a more methodologically sound procedure, since within one questionnaire, it becomes possible to establish the reliability and validity of the five basic needs as separate entities. Wahba and Bridwell (1976) nonetheless point out that none of the scales that operationalized Maslow's categories report test-retest reliability coefficients or predictive validity: furthermore, the intercorrelation of items within categories where reported - are usually not high. Barling (Note 1) however, reported rather high reliability coefficients for the Kuder Richardson 20 (Ferguson, 1951) for both English and Afrikaans-speaking samples for all five needs (range: ,85-,91). Such questionnaires have their draw-backs however, as there is the possibility that response set might become operative (cf. Kendall, Note 2). Furthermore, such questionnaires could not be used with illiterate individuals.

The vast majority of paper-and-pencil questionnaires reported in the literature have used the porter (1961) NSQ in some form or another (e.g., Howell, et.al., 1975; Roberts, et.al., 1971; Lawler \& Suttle, 1971; Alderfer, 1969; Wofford, 1971; Blunt, 1973; Slocum, 1971; and Slocum, et.al., 1971). However, a number of problems regarding the psychometric properties of this questionnaire have been raised, casting doubt on the validity of any results obtained from it. Roberts, et.al. (1971) argue that pointing to how important something is, or how much of it there should be at any particular time cannot be considered an easy task. Secondly, individuals may not respond to questions as to how much there is only in terms of its current dimension; rather, feelings about how much there should be and its relative importance may well enter into the issue of the current status of the need! Thirdly, Wahba and Bridwell (1976) point out that there are insufficient items in this particular questionnaire, and that no reliability data is presented. Fourthly, Wall and Payne (1973) make the point that results from this questionnaire report job deficiencies far more often than job satisfaction. Finally, Ewen (1967) has shown that importance measures might not produce adequate results regarding 
satisfaction dimensions. Consequently, exclusive reliance on this measuring device in any form might thus be unwarranted and, in effect, serve to obstruct research progressing in the area of work motivation and job satisfaction.

An approach at times suggested for assessing Maslow's theory is that of factor analysis. A major problem with this technique as Huizinga (1970) points out however, is that interpretations in a factor analytic study are highly subjective; furthermore, different factor analytic studies tend to yield different results for different researchers. Together, these two problems make factor analysis an unsuitable technique for assessing Maslow's theory.

Consequently, it is suggested that the most suitable methodological approach might be (standardized) paper-and-pencil questionnaires, administered longitudinally. Nevertheless, longitudinal studies have an inherent problem, as individuals tend to leave organizations (cf. Hall \& Nougaim, 1968). At the end of such studies, therefore, there may not be sufficient subjects in the sample to permit an adequate statistical analysis. However, neither Trexler and Schuh (1971) nor Lawler and Suttle (1972) encountered this problem. Cross-sectional data might yield information regarding the static nature of the need hierarchy. Using cross-lagged panel correlation techniques (Pelz \& Andrews, 1964), causal information about the relationship between the motivation and satisfaction of the needs may be inferred.

In view of all the above, a critical problem arises in evaluating the application of Maslow's theory in the industrial setting; none of the investigations reported were sufficiently rigid methodologically or psychometrically. It is therefore questionable whether this theory can really be rejected on the basis of the studies reported. Consequently, any conclusions reached must necessarily be considered as tentative.

\section{CONCLUSION}

From the above, it is apparent that although some studies claim to "validate" the use of Maslow's motivation theory in the industrial context, much doubt is cast on some of the theory's most basic hypotheses in this specific context. For example, it has been shown that the rank order of the needs could well differ from culture to culture, while the dynamic nature of the need hierarchy has not always been supported. Consequently, a conservative conclusion, made both implicitly and explicitly by many authors (including Maslow himself), is that far more research is required before any firm conclusions about the applicability of this theory within industry can be advanced, particularly as both the methodology and measurement 
techniques used to refute this theory, are themselves rather questionable. Should this theory nonetheless be found to be applicable in the work situation, its implementations would still be problematic because of the lack of operational definitions for the industrial situation.

With regard to the need for further research, two points should be enumerated. First, there is the possibility that this theory, in its present form, might not be amenable to empirical research in the industrial context because of its high level of abstraction. This might not be surprising though, as the application of this motivation theory to the industrial situation was certainly not one of Maslow's original intentions (cf. Hill, 1974). The second point involves the direction which future research should take. It would appear essential that any possible relationship between the self actualization need and productivity be established as this is directly relevant to the utility of this theory for the industrial situation (an issue not dealt with by Wahba and Bridwell (1976)), i.e., if it is to have utility as a theory of work motivation. Lawler (1973) maintained that to be both adequate and effective as a theory of work motivation, the criteria of the prediction and control of behaviour in organizations should be met. On the basis of the studies reviewed, however, it is somewhat doubtful whether these two criteria can, in fact, be fulfilled. It is therefore questionable whether Maslow's theory of motivation is adequate as a theory of work motivation.

In conclusion however, it can be seen that results from available studies do not conclusively support the utility and applicability of this theory within or for the industrial and organizational context. Indeed, the contention (e.g., Hill, 1974; Wahba \& Bridwell, 1976) that Maslow's theory is a general theory of motivation rather than a theory of work motivation, although conservative, seem justified. Should future research continue to fail to provide support for such an application, it is nonetheless appropriate to state that Maslow's theory has proved beneficial by stimulating considerable interest and research regarding work motivation. For example, a number of approaches to work motivation (e.g., McGregor's Theory X Theory Y formulations (1960); Hall and Nougaim's career stages model (1968); and Alderfer's $E R G$ theory (1969) are the result of the attempt to apply Maslow's theory of motivation within the industrial context, while the writings of others (e.g., Argyris, 1964; and Schein, 1965) have been influenced to some considerable extent by Maslow's motivation theory. 
The present article critically reviews the application of Maslow's motivational theory within the industrial situation. It is pointed out that although this theory is frequently applied in this context, its utility and applicability in such a situation has not been conclusively demonstrated on the basis of the research conducted. Furthermore, a distinction is drawn between studies assessing the applicability of this theory within the industrial situation, and those assessing its utility for industry. The need for further research, particularly to establish whether any relationship exists between the need for self actualization and productivity (i.e., the utility of the theory for the organization), it thus advanced. Finally, it is suggested that in terms of the criteria of the prediction and control of behaviour in organizations, this theory might not be adequate as a theory of work motivation.

\section{REFERENCE NOTES}

1. Barling, J.I. The application of Maslow's need hierarchy and Bass's accelerate-decelerate formulation to three levels of mining personnel. Unpublished Masters Dissertation, University of the Witwatersrand, Johannesburg, 1976.

2. Kendall, I.M. An exploratory attempt to construct motivation scales for application to preliterates: a critical evaluation. National Institute for Personnel Research, CSIR Special Report PERS 188, Johannesburg, 1973.

\section{REFERENCES}

Alderfer, C.P. An empirical test of a new theory of human needs. Organizational Behavior and Human Performance, 1969, 4, 142-175.

Alderfer, C.P. Existence, relatedness and growth. New York: The Free Press, 1972.

Argyris, C. Integrating the individual and the organization. New York: John Wiley, 1964.

Backer, W. Motivating Black Workers. Johannesburg: McGraw-Hill, 1973.

Barling, J.I. An empirical test of the career stages alternative to Maslow's need hierarchy concept in one industrial setting. South African Journal of Psychology. 1976, 6, in press.

Blackler, F., \& Williams, R. Peoples' motives at work. In P.B. Warr (Ed.), Psychology at Work. Great Britain: Penguin Books, 1971.

Blunt, P. Cultural and situational determinants of job satisfaction amongst management in South Africa - a research note. The Journal of Management Studies, 1973, 10, 131-140.

Centers, R. Motivational aspects of occupational stratification. The Journal of Social Psychology, 1948, 28, 187-217.

Centers, R., \& Bugental, D.E. Intrinsic and extrinsic job motivation among different segments of the working population. Journal of Applied Psychology, 1966, 50, 193197.

Eilon, S. Editorial: The mythology of self actualization. Omega: The International Journal of Management Science, 1975, 3, 623-630. 
Ewen, R.B. Weighting components of job satisfaction. Journal of Applied Psychology, 1967, 51, 68-73.

Ferguson, G.A. A note on the Kuder-Richardson formula. Educational and Psychological Measurement, 1951, 11, 612-615.

Goble, F. The Third Force: The Psychology of A.H. Maslow. New York: Grossman Publishers, 1970.

Grigaliunas, B. \& Weiner, Y. Has the research challenge to motivation hygiene been conclusive? An analysis of critical studies. Human Relations, 1974, 27, 839-871.

Hall, D.T. \& Nougaim, K.E. An examination of Maslow's need hierarchy in an organizational setting. Organizational Behaviour and Human Performance, 1968, 3, 12-35.

Hill, R. Abraham Maslow: The philosopher who ranked human needs. International Management, 1964, November, 47-51.

Howell, P., Strauss, J., \& Sorensen, P.F. Research note: Cultural and situational determinants of job satisfaction amongst management in Liberia. The Journal of Management Studies, 1975, 12, 225-227.

Huizinga, G. Maslow's need hierarchy in the work situation. Groningen: Wolters-Noordhof Publishing Co., 1970.

Lawler, E.E. Motivation in work organizations. Monterey, Calif.: Brooks/Cole, 1973.

Lawler, E.E., \& Suttle, J.L. A casual correlational test of the need hierarchy concept. Organizational Behaviour and Human Performance, 1972, 7, 265-287.

Lyman, E.L. Occupational differences in the value attached to work. American Journal of Sociology, 1955, 61, 138-144.

Maslow, A.H. Eupsychia - the good society. Journal of Humanistic Psychology, 1961, 1, 111.

Maslow, A.H. Criteria for judging needs to be instinctoid. Acta Psychologia, 1964, 23, 86-87.

Maslow, A.H. Eupsychian Management - A Journal. Homewood, I11.: Irwin-Dorsey, 1965.

Maslow, A.H. Toward a Psychology of Being. (2nd ed.). Van Nostrand Reinhold Co., 1968.

Maslow, A.H. Motivation and Personality. (2nd ed.) Harper and Row Publishers, 1970.

Maslow, A.H. On eupsychian management. In A.H. Maslow (Ed.). The Farther Reaches of Human Nature. Pelican Books, 1971.

Parke, E.L. \& Tausky, C. The mythology of job enrichment: Self actualization revisited. Personnel, 1975, Sept-Oct., 12-21.

Pelz, D.C. \& Andrews, F.M. Detecting causal priorities in panel study data. American Sociological Review, 1966, 29, 836-848.

Pigors, P. \& Myers, C.A. Personnel Administration: A Point of View and a Method (6th ed.). New York: McGraw-Hill, 1967.

Porter, L.W. A study of perceived need satisfaction and importance in bottom and middle management jobs. Journal of Applied Psychology, 1961, 45, 1-10.

Roberts , K.H., Walter, G.A. \& Miles, R.E. A factor analytic study of job satisfaction items designed to measure Maslow categories. Personnel Psychology, 1971, 24, 205-220.

Sanford, A.C. A cross cultural study of industrial motivation. Southern Quarterly, 1970, 8, 146-161.

Schein, E.H. Organizational psychology. Englewood-Cliffs, New Jersey: Prentice-Hall Inc., 1965.

Slocum, J.W. A comparative study of the satisfaction of American and Mexican operatives. Academy of Management Journal, 1971, 14, 89-97.

Slocum, J.W., Topichak, P.M. \& Kuhn, D.G. A cross cultural study of need satisfaction and need importance for operative employees. Personnel Psychology, 1971, 24, 435-445. 
Trexler, A.J. \& Schuh, A.J. Personality dynamics in a military training command and its relationship to Maslow's motivational hierarchy. Journal of Vocational Behaviour, 1971, 1, 245-253.

Wahba, M.A. \& Bridwell, L.G. Maslow reconsidered: A review of research on need hierarchy theory. Organizational Behaviour and Human Performance, 1976, 15, 212-240.

Wall, T.D. \& Payne, R. Are deficiency scores deficient? Journal of Applied Psychology, 1973, 58, 322-326.

Wofford, J.C. The motivational bases of job satisfaction and job performance. Personnel Psychology, 1971, 24, 501-508. 